\title{
Sistem Monitoring dan Kontrol Motor AC Berbasis SCADA
}

\author{
Ta'ali1, Fivia Eliza ${ }^{2}$ \\ 1,2 Universitas Negeri Padang \\ Jl. Prof Dr. Hamka Air Tawar, Padang, Indonesia \\ taaliftunp@gmail.com¹, fivia_eliza@ft.unp.ac.id ${ }^{2}$
}

\begin{abstract}
The SCADA-based AC motor monitoring and control system is a three-phase induction motor monitoring and control system. Motor speed regulation feedback is obtained from the tacho generator which is connected to the pulleys. The SCADA program manages inverter and microcontroller communications so that the process of monitoring the speed of an induction motor is done through a computer. Induction motor speed regulation using VSD as an inverter functions to adjust the source frequency so that the motor speed can be adjusted. Communication between VSD, PLC and SCADA uses the MODBUS protocol to monitor the performance of the induction motor. The main equipment uses ATV12HU22M3 inverter and CQM1H PLC. The CXProgrammer and CIMON software function to manage and monitor in real time the system. The results of the induction motor settings can be adjusted with VSD speeds ranging from 0-50 Hz. PLC as master control and SCADA function as distance controller.
\end{abstract}

Keywords - Inverter,VSD, PLC, SCADA and Modbus

Abstrak- Sistem monitoring dan kontrol motor AC berbasis SCADA merupakan sistem monitoring dan kontrol kecepatan putaran motor induksi tiga fasa. Umpan balik pengaturan kecepatan motor diperoleh dari tacho generator yamg terhubung ke katrol. Program SCADA mengatur komunikasi inverter dan mikrokontroler sehingga proses monitoring kecepatan motor induksi dilakukan melalui komputer. Pengaturan kecepatan motor induksi menggunakan VSD sebagai inverter berfungsi mengatur frekuensi sumber sehingga kecepatan motor dapat diatur. Komunikasi antara VSD, PLC dan SCADA menggunakan protokol MODBUS untuk memonitoring kinerja dari motor induksi. Peralatan utama menggunakan inverter ATV12HU22M3 dan PLC CQM1H. Software CX-Programmer dan CIMON berfungsi untuk melakukan pengaturan dan monitoring secara real time pada sistem. Hasil pengaturan motor induksi dapat diatur kecepatannya dengan VSD mulai dari 0-50 Hz. PLC sebagai master kontrol dan SCADA berfungsi sebagai pengendali jarak.

Kata kunci- Inverter,VSD, PLC, SCADA dan Modbus.

\section{Pendahuluan}

Penggunaan motor induksi tiga fasa untuk aplikasi di mesin-mesin industri telah banyak digunakan pada dunia Industri. Motor induksi tiga fasa Mempunyai konstruksi yang sederhana sehingga mudah dalam perawatannya, bahkan bisa dikatakan tanpa perlu perawatan yang khusus. Pengaturan kecepatan motor induksi tiga fasa dapat dilakukan dengan empat cara yaitu dengan mengubah jumlah kutup, mengatur tegangan sumber, mengatur frekuensi sumber dan menambahkan tahanan luar (khusus untuk rotor belitan). Pengaturan dengan mengubah jumlah kutup dapat dilakukan dengan mengubah konstruksi stator, sedangkan untuk menambahkan tahanan luar hanya bisa dilakukan pada motor induksi rotor belitan. Pengaturan kecepatan motor induksi yang bisa dilakukan dengan leluasa adalah dengan mengubah tegangan dan frekuensi sumber. [1] Pengaturan kecepatan motor induksi bisa dilakukan menggunakan local controller atau kontrol ditempat, namun sudah ada beberapa yang mulai mengembangkan remote controller atau kontrol jarak jauh. Banyak keuntungan yang bisa didapatkan dengan mengembangkan remote controller. Yang paling utama adalah kemudahan user dalam melakukan controlling, monitoring dan data aquisition secara real time.

Dalam pengoperasiannya motor induksi tiga fasa membutuhkan sumber tegangan arus bolak balik tiga fasa. Motor induksi tiga fasa dapat dibentuk dalam hubungan bintang (Y) atau segitiga $(\Delta)$. Banyaknya penggunaan motor induksi di industri, dibutuhkan pengendali dan kontrol untuk menjalankan dan memonitoring keadaan motor tersebut. Pengendalian dan kontrol motor saat ini banyak menggunakan PLC (Programabble Logic Controller) sebagai controller, tetapi belum banyak yang menggunakan touch panel dan SCADA sebagai pusat kendalinya. Pengendalian motor dengan sistem konvensioanal dan rangkaian elektromagnet akan memerlukan pengkabelan (wiring) yang cukup rumit, sehingga bila ada kerusakan akan memerlukan waktu lama dalam perbaikan. Dalam proses produksi kehilangan waktu produksi berarti kehilangan jumlah produksi, dan mengakibatkan kerugian yang cukup besar bagi perusahaan. Sistem monitoring mesin dengan konvensional tidak dapat mendapatkan data yang akurat 
dan real time. Terkadang terjadi kesalahan ketika pencatatan parameter pada motor, tegangan, dan arus, yang terbaca pada alat ukur. Kesalahan yang terjadi bisa disebabkan kesalahan pembacaan (human error) atau kesalahan alat ukur. [2]-[7]

Guna memudahkan pengontrolan kecepatan motor induksi tiga fasa, yang termonitoring dan memiliki data yang real time maka monitoring dan kontrol motor dihubungkan dengan sistem SCADA (Supervisory Control And Data Acquisition).

\section{Pengaturan Kecepatan Motor Induksi}

Motor induksi merupakan motor yang banyak digunakan pada industri, bisnis transportasi dan lain-lain. Konstruksinya yang kokoh (robust) merupakan keunggulan dari motor induksi disamping harga yang murah dan bebas perawatan, sehingga peranan motor DC sekarang banyak digantikan oleh motor induksi. Pada umumnya motor induksi digunakan pada kecepatan putaran tetap. Berdasarkan survei, konsumsi daya pada motor dengan kecepatan konstan lebih besar dibanding dengan motor kecepatan variabel untuk berbagai beban. [8]

Namun motor induksi tiga fasa tidak terlepas dari beberapa kekurangan seperti arus start yang besar dan nilai overshoot motor yang mempengaruhi performa motor induksi tersebut [9]. Prinsip kerja motor induksi tiga fasa adalah berdasarkan induksi elektromagnetik. Jika kumparan stator dihubungkan dengan sumber tegangan sinusoida tiga fasa, maka pada kumparan stator akan mengalir arus yang memiliki beda fasa $120^{\circ}$ tiap fasanya dan menimbulkan medan magnet yang berputar terhadap ruang yang sering dinamakan dengan kecepatan sinkron $\left(\mathrm{n}_{\mathrm{s}}\right)$. Kecepatan sinkron dapat dihitung menggunakan rumus sebagai berikut [10]-[16].

$$
n_{s}=\frac{120 \cdot f_{s}}{p}
$$

$$
\begin{aligned}
& \text { dimana } \\
& \mathrm{n}_{\mathrm{s}}=\text { putaran sinkron }(\mathrm{rpm}) \\
& \mathrm{f}_{\mathrm{s}}=\text { frekuensi listrik sumber }(\mathrm{Hz}) \\
& \mathrm{p}=\text { jumlah kutub lilitan stator }
\end{aligned}
$$

Medan magnet yang dihasilkan pada kumparan stator tersebut akan memotong penghantar rotor, sehingga pada penghantar rotor timbul tegangan induksi. Karena rotor merupakan rangkaian yang terhubung singkat, maka pada rotor akan mengalir arus induksi. Penghantar rotor yang dialirai arus induksi terletak dalam medan magnet yang berputar, maka pada rotor akan timbul gaya dan akan menghasilkan torsi. Jika torsi yang dihasilkan cukup untuk memutar rotor, maka motor akan berputar dengan kecepatan sebesar $\mathrm{n}_{\mathrm{r}}$. Pada motor induksi kecepatan putaran rotor $\left(\mathrm{n}_{\mathrm{r}}\right)$ selalu lebih kecil dari kecepatan putaan sinkron $\left(\mathrm{n}_{\mathrm{s}}\right)$. Perbedaan antara putaran sinkron dengan putaran rotor disebut Slip (s). Nilai slip dihitung dengan persamaan sebagai berikut [10] - [16]:

$$
s=\frac{n_{s}-n_{r}}{n_{s}} \times 100 \%
$$

\section{dimana:}

$$
\begin{aligned}
& \mathrm{s}=\operatorname{slip}(\%) \\
& \mathrm{n}_{\mathrm{s}}=\text { putaran sinkron }(\mathrm{rpm}) \\
& \mathrm{n}_{\mathrm{r}}=\text { putaran rotor }(\mathrm{rpm})
\end{aligned}
$$

Pada saat rotor diam maka frekuensi rotor (fr) sama dengan frekuensi stator $(f s)$. Pada saat rotor berputar maka frekuensi rotor akan dipengaruhi oleh slip yang mengikuti persamaan di bawah ini:

$$
f_{r}-s . f_{s}
$$

Pengaturan kecepatan motor induksi tiga fasa dapat dilakukan beberapa cara antara lain adalah [17]-[24]:

a. Mengubah jumlah kutup. Hal ini sesuai dengan persamaan no. 2. Dimana putaran berbanding terbalik dengan jumlah kutup. Semakin besar jumlah kutup maka putaran motor yang dihasilkan akan semakin kecil. Begitu juga sebaliknya

b. Mengubah Frekuensi sumber. Hal ini sesuai dengan persamaan no 2. Dimana putaran berbanding lurus dengan frekuensi. Semakin besar nilai frekuensinya maka semakin besar pula kecepatan putaran motor yang dihasilkan.

c. Mengubah Tegangan sumber. Untuk dapat mengatur kecepatan motor induksi tiga fasa dengan variabel tegangan bisa dilihat pada persamaan torsi motor induksi sebagai berikut:

$$
\begin{aligned}
& T=\frac{P}{a}=\frac{3 \cdot E_{1} \cdot I_{2}^{\prime} \cdot \cos \varphi}{\omega} \\
& \text { Dimana }: \\
& \text { P = Daya } \\
& \text { T = Torsi } \\
& \text { E}_{1}=\text { tegangan sumber } \\
& \omega=\text { Kecepatan sudut }
\end{aligned}
$$

Dari rumusan tersebut dapat dilihat bahwa torsi berbanding lurus dengan tegangan dan arus. Semakin besar tegangan yang diinjeksikan ke motor, maka torsinya akan semakin meningkat. Meningkatnya torsi ini sebanding dengan peningkatan kecepatan motor induksi.

\section{Inverter}

Sebagai pengendali motor induksi tiga fasa diperlukan adanya sebuah inverter. Inverter merupakan sebuah alat pengatur kecepatan motor dengan mengubah nilai frekuensi yang masuk ke motor. Pengaturan nilai frekuensi ini dimaksudkan untuk memperoleh kecepatan putaran yang di inginkan atau sesuai dengan kebutuhan. [9] 
Inverter adalah rangkaian elektronika yang berfungsi untuk mengubah arus tegangan DC menjadi tegangan AC. Output suatu inverter dapat berupa tegangan AC dengan bentuk gelombang sinus (sine wave), gelombang kotak (square wave) dan sinus modifikasi (sine wave modified).

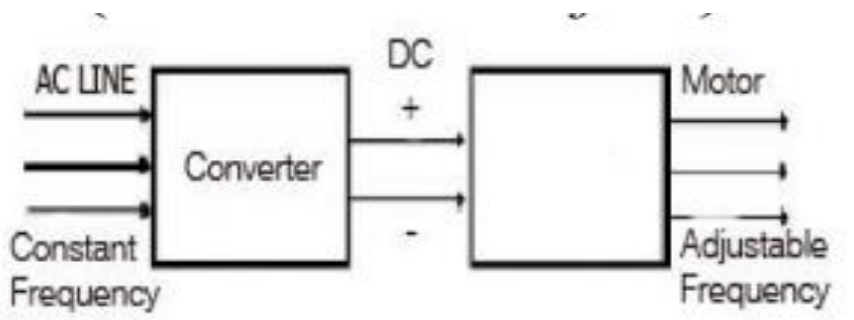

Gambar 1. Blok Diagram dari cara kerja inverter

Fungsi Inverter adalah untuk merubah kecepatan motor AC dengan cara merubah frekuensi outputnya dari rumus (1) di atas.

Hubungan antara Periode dan Frekuensi Getaran mengkuti rumus:

$\mathrm{f}=1 / \mathrm{T} ; \quad \mathrm{f}=$ frekuensi $\quad(\mathrm{Hz}=$ =siklus/detik $) ;$ dan $\mathrm{T}=$ periode waktu

Dengan mengubah frekuensi yang masuk pada motor, maka kecepatan motor akan berubah. Karena itu inverter biasa disebut juga Variable Speed Drive.

\section{PLC (Programmable Logic Controller)}

(Programmable Logic Controller / PLC) adalah suatu peralatan elektronik yang bekerja secara digital, memiliki memori yang dapat diprogram, menyimpan perintahperintah untuk melakukan fungsi khusus seperti logic, sequencing, timing, counting, dan aritmatic untuk mengontrol berbagai jenis mesin atau proses melalui modul analog atau digital Input/Output.

Fungsi utama dari sebuah PLC adalah untuk memonitor parameter proses rumit dan melakukan penyesuaian operasi proses yang sesuai. Hal itu dapat diprogramkan, dikendalikan dan dioperasikan dengan memperhatikan kondisi dari sistem khususnya input device. Operator PLC diharapkan dapat menggambarkan alur dari ladder diagram dengan suatu papan tombol (input) ke suatu tampilan (output). Hasil penggambaran akan diubah jadi bahasa komputer dan dijalankan sebagai program user. [25]-[28]

PLC sendiri memiliki beberapa jenis dan tipe yang beredar di pasaran. Diantaranya yaitu PLC jenis small, medium, dan large yang diproduksi oleh Omron, Toshiba, Siemens, LG, Fuji Elektrik, dan Schneider. PLC yang digunakan dalam penelitian ini adalah produk dari Omron karena konsep pemrograman yang digunakan mudah, menggunakan penghubung RS-485 (Multidrop) yaitu dapat dihubungkan dengan beberapa PLC sekaligus, kabel serial menggunakan USB yang kompatibel dengan banyak komputer, harga relatif kompetitif dibanding PLC merk lain dengan kualitas yang sama. Untuk PLC dari pabrikan Omron sendiri memiliki beberapa macam tipe salah satunya yaitu PLC CQM1H Modular.

\section{Sistem SCADA}

SCADA merupakan singkatan dari Supervisory Control And Data Acquisition yang mengandung pengertian sekumpulan peralatan yang bekerja membentuk suatu kesatuan dan bekerja bersama - sama yang saling berkomunikasi untuk menjalankan fungsi pengukuran, kontrol, dan permintaan/ pengiriman data. SCADA digunakan untuk membantu mendapatkan sistem pengoperasian yang optimum dengan kenyataan yang ada dilapangan yang berupa kekurangan maupun kelebihan yang terdapat pada suatu sistem. SCADA terdiri dari perlengkapan hardware dan software. [2]-[3]

Fungsi dari Sistem SCADA :

a. Telecontrol berfungsi melakukan perintah Remote Control (Open / Close) terhadap peralatan yang berada dilapangan.

b. Telesignaling berfungsi

mengumpulkan data status dan alarm (Open, Close, power Supply fault, indikasi relay atau parameter lainnya) yang dianggap perlu, yang dapat membantu operator dalam memonitor peralatan yang berada dilapangan. Dengan ini diharapkan gangguan pada bagian tertentu dapat dideteksi lebih cepat karena pemantauan dari pusat kontrol dan diketahui dalam waktu yang real time.

c. Telemetering berfungsi mengukur beban yang terpasang pada alat ukur tenaga listrik (Arus, Tegangan, Daya Aktif, Frekuensi dll) dan semua peralatan yang berada dilapangan. Hasil pemantauan ini, selain digunakan sebagai pencatat data pengoperasian alat juga dapat digunakan dalam kaitannya untuk melakukan Remote Control.

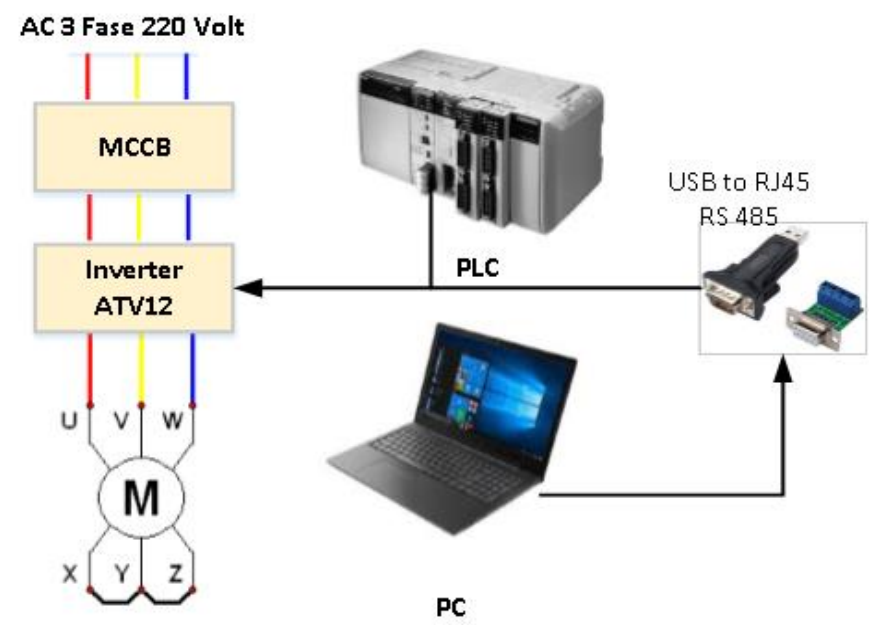

Gambar 2. Rangkaian RJ45 ke PLC Omron

\section{Pengaturan Kecepatan Motor dengan Protokol Modbus Via PLC dan SCADA}


Pada proses ini menggunakan sistem yang terdiri dari system komunikasi PLC dengan Altivar dengan sistem komunikasi antara PLC dengan PC. Hubungan antara PLC dengan Altivar yaitu dihubungkan melalui komunikasi modbus serial. Sehingga parameter kecepatan dapat dengan mudah terbaca melalui register yang menyimpan kecepatan dari motor.Hubungan antara PLC dengan PC (SCADA) yaitu melalui komunikasi modbus. Dalam hal ini diperlukan suatu modul komunikasi yang mendukung komunikasi modbus TCP.

Komunikasi antara PLC dengan Altivar adalah komunikasi modbus serial yang dihubungkan dengan terminal RJ45. Pada PLC dihubungkan pada modul . Modul tersebut adalah modul Ethernet pada PLC. Sehingga dikarenakan terminal pada Altivar adalah RS-485 maka diperlukan suatu modul konverter. [2]-[7]

Serial pin RJ 45 dapat dilihat pada tabel 1.

Tabel 1. Serial pin RJ 45

\begin{tabular}{llll}
\hline No & PLC & Nama & RJ45 \\
\hline 1 & A & + & Terminal 4 \\
\hline 2 & B & - & Terminal 5 \\
\hline 3 & SG & GROUND & \\
\hline
\end{tabular}

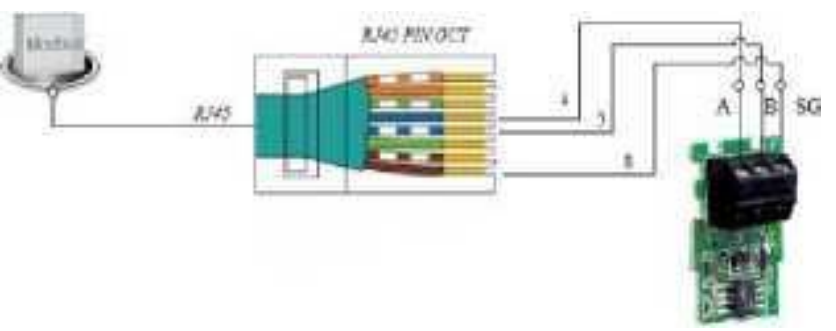

Gambar 3. Rangkaian RJ45, PLC CQM1H, Altivar 12

\section{Metode}

Pengendalian kecepatan putaran motor induksi dapat dilakukan dengan beberapa cara diantaranya dengan kendali tegangan dan frekuensi yang dikenal dengan kendali V/f konstan. Keuntungan dari metode kendali V/f konstan adalah memiliki struktur kendali yang sederhana, mudah dan cepat diprogram serta dapat dioperasikan dengan metode kendali loop terbuka tanpa pengendali kecepatan atau dengan pengendali kecepatan, sehingga secara ekonomis lebih murah.

Metode untuk mengkodekan sinyal analog menjadi durasi lebar pulsa dengan logika high dan low tersebut adalah Space Vector PWM. Dalam perancangan rangkaian kontrol kecepatan diharapkan dapat mengatur kecepatan motor induksi tiga fasa dengan putaran yang lebih halus (smooth) dan diharapkan kecepatan motor dapat mengikuti kecepatan acuannya.

Kendali kecepatan motor induksi tiga fasa dengan pengaturan frekuensi menggunakan sumber tegangan 1 - fasa menurut [3] dalam dilakukan dengan beberapa metoda diantaranya adalah sebagai berikut :

1. Menggunakan metode Single-phase to three-phase ac/dc/ac converter with a dc boost chopper

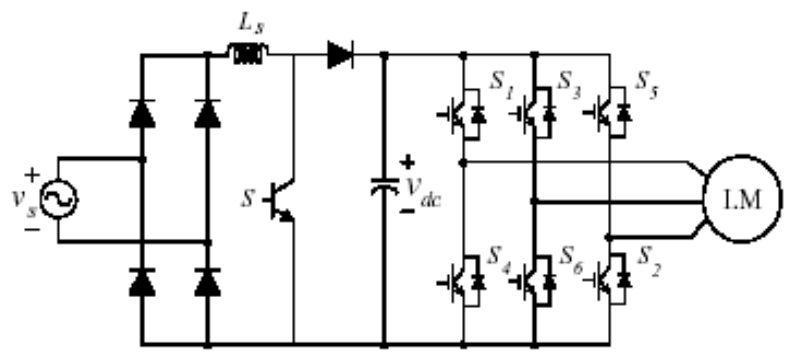

Gambar 4. Single-phase to three-phase ac/dc/ac converter with a dc boost chopper.

2. Menggunakan metode Single-phase to three-phase ac/dc/ac PWM converter

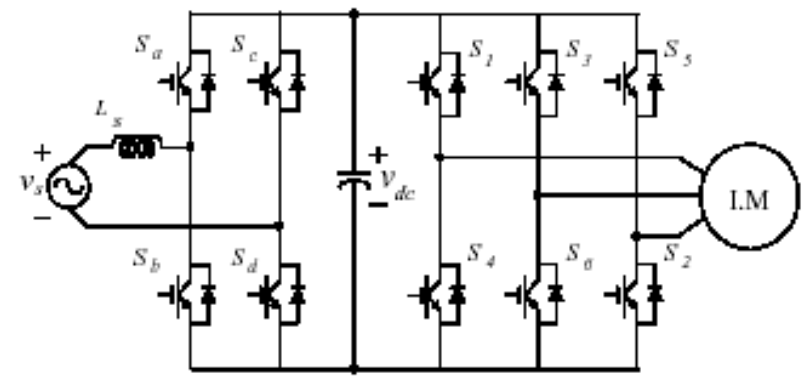

Gambar 5. Single-phase to three-phase ac/dc/ac PWM converter.

3. Menggunakan metode Single-phase half-bridge plus two-leg three-phase ac/dc/ac PWM converter topology

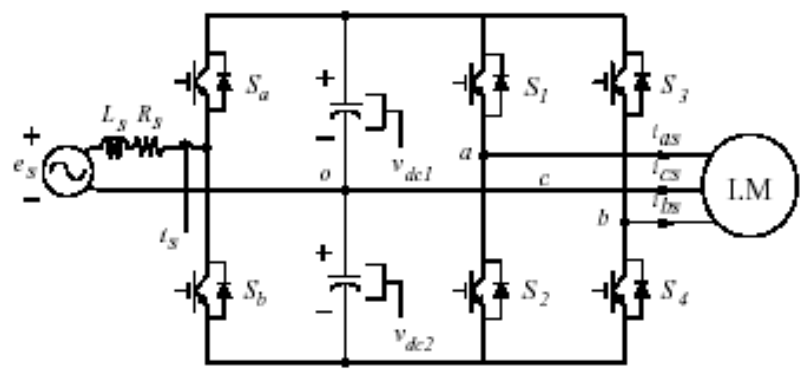

Gambar 6. Single-phase half-bridge plus two-leg threephase ac/dc/ac PWM converter topology

\section{HASIL DAN PEMBAHASAN}

Pengukuran kecepatan motor induksi pada penelitian ini menggunakan beberapa percobaan yaitu Start/Stop, Reverse/Forward. Pada setiap percobaan frekuensi diubah-ubah untuk mengetahui kecepatan putaran motor dan berapa lama motor tersebut dihentikan atau dibalik 
arah putarannya. Hasil pengukurannya seperti pada tabel 2 .

Tabel 2. Kecepatan Motor Arah Maju

\begin{tabular}{ccccc}
\hline No & Frekuensi & Volt & Rpm & Arus (A) \\
\hline 1 & 5 & 22 & 148 & $1,9 \mathrm{~A}$ \\
\hline 2 & 10 & 44 & 297 & $2,3 \mathrm{~A}$ \\
\hline 3 & 15 & 62 & 448 & $2,5 \mathrm{~A}$ \\
\hline 4 & 20 & 82 & 602 & $2,6 \mathrm{~A}$ \\
\hline 5 & 25 & 99 & 751 & $2,6 \mathrm{~A}$ \\
\hline 6 & 30 & 119 & 905 & $2,7 \mathrm{~A}$ \\
\hline 7 & 35 & 133 & 1052 & $2,7 \mathrm{~A}$ \\
\hline 8 & 40 & 157 & 1204 & $2,7 \mathrm{~A}$ \\
\hline 9 & 45 & 176 & 1353 & $2,7 \mathrm{~A}$ \\
\hline 10 & 50 & 194 & 1500 & $2,8 \mathrm{~A}$ \\
\hline
\end{tabular}

Tabel 3. Kecepatan motor Arah mundur

\begin{tabular}{|c|c|c|c|c|}
\hline No & $\begin{array}{c}\text { Frek. } \\
\text { (Hz) }\end{array}$ & $\begin{array}{c}\text { Volt } \\
\text { (V) }\end{array}$ & Rpm & Arus ( A ) \\
\hline 1 & 5 & 22 & 147 & $1,9 \mathrm{~A}$ \\
\hline 2 & 10 & 43 & 298 & $2,3 \mathrm{~A}$ \\
\hline 3 & 15 & 61 & 449 & $2,5 \mathrm{~A}$ \\
\hline 4 & 20 & 81 & 600 & $2,6 \mathrm{~A}$ \\
\hline 5 & 25 & 99 & 752 & $2,6 \mathrm{~A}$ \\
\hline 6 & 30 & 118 & 900 & $2,7 \mathrm{~A}$ \\
\hline 7 & 35 & 132 & 1050 & $2,7 \mathrm{~A}$ \\
\hline 8 & 40 & 156 & 1203 & $2,7 \mathrm{~A}$ \\
\hline 9 & 45 & 175 & 1355 & $2,7 \mathrm{~A}$ \\
\hline 10 & 50 & 194 & 1500 & $2,8 \mathrm{~A}$ \\
\hline
\end{tabular}

\section{PENUTUP}

Dari hasil Pengaturan Kecepatan Motor Dengan Protokol Modbus via PLC Dan SCADA dapat disimpulkan bahwa :

1. Kecepatan motor induksi tiga fasa dapat diatur dengan rentang yang luad secara melalui remote controller dengan adanya integrasi antara PLC, Altivar 61.

2. PLC dan inverter dapat dihubungkan dengan sistem komunikasi dengan protokol Modbus melalui kabel RJ 45.

3. Kecepatan motor dan kondisi (on/off) motor dapat diketahui dengan cepat melalui komunikasi sistem SCADA dan terbaca secara real time.

4. Pada pengukuran arah putaran (baik forward maupun reverse) kenaikan frekuensi seiring dengan tegangan dan putaran motor, sedangkan arusnya cenderung tetap.
[1] Yusnan Badruzzaman, 2015. Sistem Monitoring Kendali Motor Induksi Tiga Fasa Dengan Variable Speed Drive Berbasis PLC Dan SCADA. Orbith Vol. 11 No. 2 Juli 2015 p.147 - 152

[2] Aeri Sujatmiko dan Setyo Supratno, 2018. Pengendali dan Monitoring Motor 3 Phase, Berbasis Scada Wonderware 10.1 dan Touch Panel Omron Type NB10-TW1B. SENTER 2018, 1 - 2 Desember 2018, pp. 9-18

[3] D. Bailey, E. Wright, Practical SCADA for Industry, Newnes, Burlington, MA, USA, 2003, p.298.

[4] D. Patterson, Citect RS232 ASCII Protocol, http://www.control.com/thread/1026197309, 2010.

[5] Anon., LG Variable Frequency Drive IG5 Series Manual Book, Instalation, Operation and Maintenance Instruction, http://www.lgis.com, 2010.

[6] Barry G. Woodlard, H. Kristiono, 2003. Elektronika Praktis, Edisi Pertama,Jakarta: Pradnya Paramita,

[7] Chapman, Stephen J., 2004, Electric Machinery Fundamentals, Fourth Edition, Boston: McGraw-Hill, Inc.

[8] Endro Wahjono, 2015. Pengaturan Kecepatan Motor Induksi Sebagai Penggerak Mobil Listrik Dengan Kontroler Fuzzy Logic Berbasis Direct Torque Control. Jurnal Ilmiah Mikrotek Vol. 1, No.3 2015 P A G E 136-144

[9] Fatih Mutammimul Wildan1, Ermanu Azizul Hakim2, Diding Suhardi3 . Sistem Pengaturan Kecepatan Motor Induksi Tiga Fasa Menggunakan Kontroler PID Berbasis Genetic Algorithm. KINETIK, Vol.1, No.1, Mei 2016, Hal. 23-32

[10] Datta, S.M., 2005, Power Electronics and Control, Reston Va, Reston Publishing Co. Inc.

[11] Dong-Choon Lee dan Young-Sin Kim, 2003, Control of Single-Phase to Three-Phase AC/DC/AC PWM Converters for Induction Motor Drives, Journal IEEE

[12] Dutton, Ken dan Thompson, Steve, 2002, The Art of Control Engeenering, New York: Addison Wesley..

[13] George M Chute, Robert D. Chute, 1991. Electronic in Industri, Edisi 5, Kogakusha: mcGreaw-Hill, Ltd.

[14] Fitzgerald A.E., Charles Kingsley Jr., dan Stephen D. Umans, 2003, Electric Machinery, Sixth Edition, Boston: McGraw-Hill Companies, Inc..

[15] Kuo, 2004. Automatic Control System, New Jersey: Prentice-Hall Inc., Englewood Cliffs.

[16] Malvino, 2005. Electronics Device, Singapore: McGraw Hill Company.

[17] Pillay $\mathrm{P}$ and Brzezinski, Induction motor performance when fed from single to three phase converter, IEEE No. 90/CH 29.35- 5/90/0000-004, 1990.

[18] Rashid, M.H., 2005. Power Electronics, New Jersey: Prentice Hall Inc..

[19] Zakir Yahya, Ta'ali, Pembuatan Alat Praktikum Trainer Kontrol Motor Induksi Untuk Meningkatkan Pembelajaran Matakuliah Rancangan Kontrol Listik konvensional, Penelitian UNP, 2007, Sumber Dana TPSDP.

[20] Ahyanuardi, Ta'ali, 2010, Visualisasi Pembelajaran Sistem Pengaturan Motor Induksi 1 Fasa Dan 3 Fasa Dengan Perubahan Frekuensi Dan Sumber Masukan Satu Fasa. Penelitian UNP tahun 2010, Sumber dana DP2M.

[21] Ta'ali, 2011, Sistem Pengendali Motor Induksi 3 Fasa Dengan Pengaturan Frekuensi Dan Sumber Masukan Satu Fasa, Penelitian UNP, Sumber Dana DIPA UNP.

[22] Ta'ali, 2015, Pembuatan Modul Trainer Sistem Pengendali Motor Induksi 3 Fasa Dengan Pengaturan Frakuensi, Penelitian UNP tahun 2015, Sumber Dana DIPA UNP.

\section{REFERENSI}


[23] Ibnu Safmid, Ta'ali. 2018. Monitoring Kecepatan Motor DC Penguat Terpisah berbasis Mikrokontroler. Tugas Akhir. Jurusan Teknik Elektro.

[24] Rinchen Geongmit Dorjee, 2014, Monitoring and Control of a Variable Frequency Drive Using PLC and SCADA, International Journal on Recent and Innovation Trends in Computing and Communication ISSN: 2321-8169 Volume: 2 Issue: 10 pp 3092-3098, October 2014, http://www.ijritcc.org

[25] Adarsh.R.J, Narsimpur Tushar, Sujatha.M.S, 2017. Monitoring And Control System For Three Phase Induction Motor Fed By Inverter Drive Using PLC And Scada, International Journal on Recent and Innovation Trends in Computing and Communication ISSN: 23218169, Volume: 2 Issue: 11, http://www.ijmra.us

[26] Ankush Dharkar, G. H. Raisoni, Dr. P. M. Daigavane, 2017. Control Of Variable Frequency Drives With PLC: A Review, International Journal of Electrical Engineering \& Technology (IJEET), Volume 8, Issue 1, January- February 2017, pp. 45-51, www.jifactor.com
[27] Vaibhav Gupta, 2018, Induction Motor Speed Control Using PLC AND SCADA, International Research Journal of Engineering and Technology (IRJET) e-ISSN: 2395-0056, Volume: 05 Issue: 03, Mar-2018, www.irjet.net.

[28] Ms. N. M. Rao, Vidya Gaikwad, Prachi Kashid, Pavan Dandale, PLC Applications For Speed Control Of Induction Motor Through VFD, International Research Journal of Engineering and Technology (IRJET) e-ISSN: 2395 -0056, Volume: 04 Issue: 02, Feb -2017, www.irjet.net 